Review Article

\title{
Effectiveness of Mobilization with Movement on the Management of Knee Osteoarthritis: A Systematic Review of Randomized Controlled Trials
}

\author{
Gidey Gomera Weleslassie (D), Melaku Hailu Temesgen (D), Abayneh Alamer (D), \\ Gebrerufael Solomon Tsegay, Teklehaimanot Tekle Hailemariam, and Haimanot Melese \\ Department of Physiotherapy, School of Medicine, College of Health Sciences and Ayder Comprehensive Specialized Hospital, \\ Mekelle University, Mekelle, Ethiopia \\ Correspondence should be addressed to Gidey Gomera Weleslassie; gideyhawey@gmail.com
}

Received 27 September 2020; Revised 2 April 2021; Accepted 28 April 2021; Published 4 May 2021

Academic Editor: Takahiro Ushida

Copyright (C) 2021 Gidey Gomera Weleslassie et al. This is an open access article distributed under the Creative Commons Attribution License, which permits unrestricted use, distribution, and reproduction in any medium, provided the original work is properly cited.

\begin{abstract}
Background. Osteoarthritis is becoming a global major cause of pain and functional disability worldwide, especially in the elderly population. Nowadays, evidence shows that mobilization with movement (MWM) has a beneficial effect on knee osteoarthritis subjects. However, its adequacy remains unclear. Objective. To review the best available evidence for the effectiveness of MWMs on pain reduction and functional improvement in patients with knee osteoarthritis. Methods. A comprehensive search of literature was conducted using the following electronic databases: Google Scholar, PubMed, Physiotherapy Evidence Database (PEDro), Science Direct, Cochrane Library, and Scopus. Only randomized controlled trials (RCTs) were included, and the methodological quality of the studies was appraised using the PEDro scale. It was reported according to the guideline of the PRISMA statement. Results. A total of 15 RCTs having 704 participants were included. The present systematic review suggests that there were significant differences between MWM groups and control groups in terms of visual analogue scale (VAS), Western Ontario and MacMaster Universities Osteoarthritis Index (WOMAC) scale, and flexion range of motion. Conclusions. This systematic review demonstrated that MWM was effective to improve pain, range of motion, and functional activities in subjects with knee osteoarthritis.
\end{abstract}

\section{Introduction}

Osteoarthritis (OA) is a chronic degenerative disease characterized by the deterioration of the cartilage in the joints, creating stiffness, pain, and impaired movement $[1,2]$. Osteoarthritis a leading cause of pain and functional disability in both developed and developing countries, especially in the elderly population $[3,4]$.

The knee joint is the most commonly affected joint by $\mathrm{OA}$ due to its weight-bearing requirement, high mobility, and lack of intrinsic stability [5]. It leads to limitations in activities of daily life and impairment in the quality of life because of the accompanying pain and morning stiffness in the joint [6].
According to the World Health Organization (WHO), OA affects $9.6 \%$ of men and $18 \%$ of women over 60 years of age [7]. Generally, 43.4 million people in the world were affected by OA associated with a disability by the year 2020 $[8,9]$. Moreover, there is an increasing need for urgent attention to this disease because of the societal trends in the population such as aging, obesity prevalence, and joint injury, estimating that the number of people affected by OA will increase by about $50 \%$ over the next 20 years $[10,11]$.

The management of knee OA needs a multidisciplinary approach. The conservative treatment forms for knee OA comprise pharmacological and nonpharmacological modalities. Nonsteroidal anti-inflammatory drugs are mostly used for pain relief and stiffness caused by OA with their 
numerous side effects, particularly on the gastrointestinal tract, making the treatment unsustainable [12, 13], whereas the nonpharmacological treatments such as manual therapy, weight management strategies, kinesiotherapy, resistance strengthening exercise, aerobic conditioning, and physical agent modalities such as electrotherapy were used to relieve pain, to reduce or eliminate complications, and to prevent disease progression for knee OA [14-21].

Mobilization with movement (MWM) is a manual therapy technique that is used most frequently for the management of musculoskeletal conditions [22]. It was initially advocated by Brian Mulligan and has been proposed as a novel manual therapy technique to treat a variety of upper and lower limb joint-related soft tissue conditions $[23,24]$. In this technique, the physiological movement is performed in a pain-free manner [24] with accessory glides being applied in the direction towards the opposite of the previously painful movement to have the greatest improvement [25].

MWMs has shown promising various therapeutic benefits such as reduction of pain and improved range of motion $[23,26]$. The rationale for the use of MWM techniques is directed towards correcting positional faults at the joint [27].

Previous evidence has furnished the beneficial effects of MWM on different peripheral joints [23, 25, 28]. Nowadays, studies mentioned that MWM had a beneficial effect on knee OA patients. Nevertheless, its adequacy remains unclear. Therefore, the aim of this review was to analyze the effectiveness of MWM on pain reduction and functional improvement in patients with knee OA.

\section{Methods}

2.1. Design and Protocol Registration. This systematic review was conducted in accordance with the Preferred Reporting Items for Systematic Reviews and Meta-Analyses (PRISMA) guideline [29] with International Prospective Register of Systematic Reviews (PROSPERO) registration number CRD/42020193092.

2.2. Search Strategy. An extensive literature search was performed to identify all eligible randomized controlled trials from inception to September 2020. Systematic and comprehensive searches were conducted in electronic databases such as Google Scholar, Physiotherapy Evidence Database (PEDro), Scopus, Science Direct, Cochrane Library, and PubMed. The search was made using the following keywords: mobilization with movement, knee osteoarthritis, and randomized controlled trial. As the topic titles speckled among the databases, various combinations of the keywords were used: "Mulligan's mobilization/mobilization with movement/sham/placebo mobilization with movement" and "osteoarthritis/knee joint pain/Arthritis/ degenerative knee arthritis" and "randomized controlled trial."

2.3. Eligibility Criteria. Studies for this review were assessed according to the following eligibility criteria.
2.3.1. Type of Studies. Only randomized controlled trials (RCTs) published in English and full-text availability.

2.3.2. Participants. Studies were included if they recruited male and/or female, diagnosed with knee OA, and subjects above 40 years of age.

2.3.3. Interventions. Intervention groups received MWM and MWM combined with conventional therapy (usual care and exercise) for the treatment of knee OA.

2.3.4. Comparisons. The control group received sham/placebo MWM, exercise, usual care, McConnell patella taping, and Maitland mobilization.

2.3.5. Primary Outcome Measures. The Visual analog scale (VAS), numeric pain rating scale (NPRS), McMaster Universities Arthritis Index (WOMAC) scale, Time Up and Go test (TUG), and range of motion (ROM).

2.3.6. Secondary Outcome Measures. A six-minute walk test, pain-free squat angle, Aggregated Locomotor Function (ALF), and Knee injury and osteoarthritis outcome scale (KOOS).

2.4. Exclusion Criteria. The exclusion criteria established for this review were observational studies, quasiexperimental studies, studies not having full access, and RCTs published in other than English languages, and results obtained from theses/dissertations, conference proceedings, abstracts, and websites were excluded from this review.

2.5. Study Selection. The study selection process was performed by four reviewers (G. G, M. H, T. T, and H. M). Only randomized control trials and studies intervening knee $\mathrm{OA}$ with MWM were included in this review. Any disagreement between the reviewers should be consulted by two reviewers (G. S and A. A) to reach a consensus.

2.6. Hierarchy of Evidence. Four reviewers independently assessed all sources of the papers, and the level of each study was determined according to the hierarchical system of Lloyd-Smith. The level of evidence reveals the degree to which bias has been considered within study design, with a lower rating on the hierarchy indicating less bias. Merely studies that scored between $1 \mathrm{~b}$ and $2 \mathrm{a}$ on the Lloyd-Smith scale were included in this systematic review. In this approach, we could ensure that MWM for knee OA supported by this review was based on results of high-level evidence.

2.7. Data Extraction. Based on a predetermined extraction tool, three authors (G.G, A.A, and G.S) independently extracted relevant data from each article. The following data were extracted from each trial: general study information (title, authors' name, year of publication, and country of 
study), OA definition (severity measure, type, and duration), number of participants in the treatment and control group, mean follow-up time, type of treatment, mean age of the participants, inclusion and exclusion criteria of the participants, primary outcome measures, study design, study findings, and conclusions.

2.8. Risk-of-Bias Assessment. The qualities of the eligible studies were assessed using the Physiotherapy Evidence Database (PEDro) Scale [30]. The PEDro scale includes 11 items, in which the first item assesses the external validity and the remaining 10 items assess the internal validity, examining random allocation, concealment of allocation, baseline equivalence, blinding procedure, 'intention to treat' analysis, adequacy of follow-up, between-group statistical analysis, and measurement of data variability. This review considered trials with a score of 5 to 7 as moderate quality and a score of $\geq 8$ as a high-quality study (Table 1).

\section{Results}

3.1. Literature Search. A total of 1198 articles were identified by the searching strategy. After adjusting for duplicates, 768 remained. After the title and abstract screening of studies, 365 studies were expelled. Subsequently, by full content screening out of 38 articles, 15 randomized controlled trials were included in this review (1).

3.2. Description of the Studies. The characteristics of the included studies are illustrated in Table 2. The included studies were published between 2010 and September 2020. Overall, 704 participants with knee OA aged from 40 to 70 years were included. The average age of the participants ranged from $47.47 \pm(0.61)$ to $58.5 \pm(4.36)$ in the experimental group [38,44] and $47.47 \pm(0.61)$ to $59.4 \pm(6.57)$ $[38,44]$ in the control group. The follow-up duration of the experimental and control group ranged from two days to twelve months $[36,40]$, with the majority of the studies having a follow-up duration of around two to three weeks.

The mean PEDro score of the studies was 6.7 (range: 5-9) (Table 3). Two trials $[36,44]$ scored 8 , and four trials $[5,35,39,40]$ scored 9 on the PEDro scale, which was the highest possible score given the intervention, as it would not be feasible to blind clinicians.

3.3. Risk of Bias within the Studies. The methodological qualities of the included studies are summarized and reported in Table 3. Out of the 15 randomized controlled trials, 9 articles reported about the procedure of proper randomization sequence and six randomized controlled trials conducted by Shenouda [31], Gupta and Heggannavar [33], Kulkarni and Kamat [34], Kiran et al. [38], Saddam Hussain Shaik et al. [41], and Pawar et al. [42] had not stated the randomization method. Six trials reported concealed allocation, and the majority of the articles had not clearly reported a concealed allocation method. In study performance bias, merely 3 of the randomized controlled trials were found to be double-blinded and the other remaining articles are single-blinded. Six randomized controlled trials conducted by Lalnunpuii et al. [5], Rao et al. [35], Kaya Mutlu et al. [36], Bhagat et al. [39], Alkhawajah and Alshami [40], and Nigam et al. [44] had a blinded outcome assessor.

3.4. Interventions. Randomized control trials comparing the effectiveness of MWM, MWM combined with conventional physiotherapy and comparison/control group: sham/placebo MWM, and/or conventional physiotherapy, usual care, myofascial release, KT, exercise, McConnell patella taping, and Maitland mobilization intervention were included.

3.5. Outcome Measures. The outcome measures for each of the fifteen trials are presented in Table 2 All the studies included outcome measures for pain and functional disability status. The pain intensity was measured by the Visual Analogue Scale (VAS) in eleven studies [5, 31-34, 36-38, 40, 42, 44], Numerical Pain Rating Scale (NPRS) in three studies $[35,39,43]$, and KOOS in one study [41]. Functional disability status was measured by the Western Ontario and McMaster Universities Osteoarthritis Index (WOMAC) in ten studies $[5,31-33,36-38,40,43,44]$, Time Up and Go in three studies $[35,39,44]$, and 6-minute walk test in one trial [34] for subjects with knee OA.

3.6. Effects of MWM on Pain Reduction. The effects of MWM intervention in subjects with knee OA are summarized in Table 2. Out of the 15 included trials, 14 of them reported that knee pain was significantly improved in the MWM groups compared to the control group [5,31,33-44]. Only one study reported that the MWM group had no improvement in knee pain compared to the control groups [32].

3.7. Effects of $M W M$ on Knee Joint ROM. From the total included trials, nine of them had assessed knee ROM. Out of these, eight trials reported that MWM has positive effects on joint range of motion for $\mathrm{OA}$ patients compared to the control groups [5, 31, 33, 36, 38, 40,43,44]. Conversely, only one study reported that the MWM group had no improvement of knee ROM compared to the control group [32].

3.8. Effects of MWM on Functional Status. Out of the included trials, fourteen of them had assessed functional status. Out of these trials, thirteen of them had reported that MWM has positive effects on functional activities in OA patients compared to the control groups [5, 31, 33-39, 41, 43, 44]. However, two studies reported that the MWM group had no significant effect on knee functional status in patients with knee OA $[32,40]$.

\section{Discussion}

This review of RCTs has been designed to investigate the effectiveness of MWM in subjects with knee OA. To the extent of our knowledge, this is the preliminary review to 


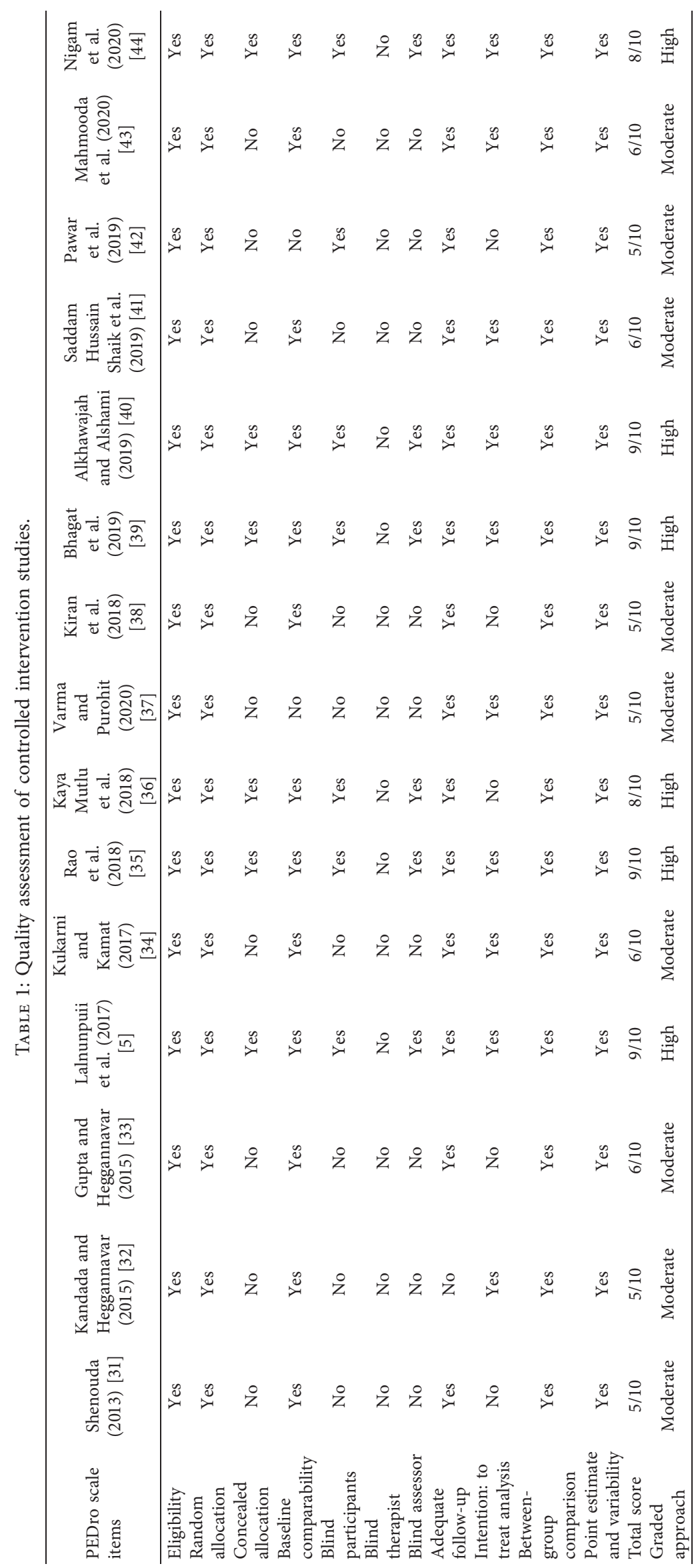




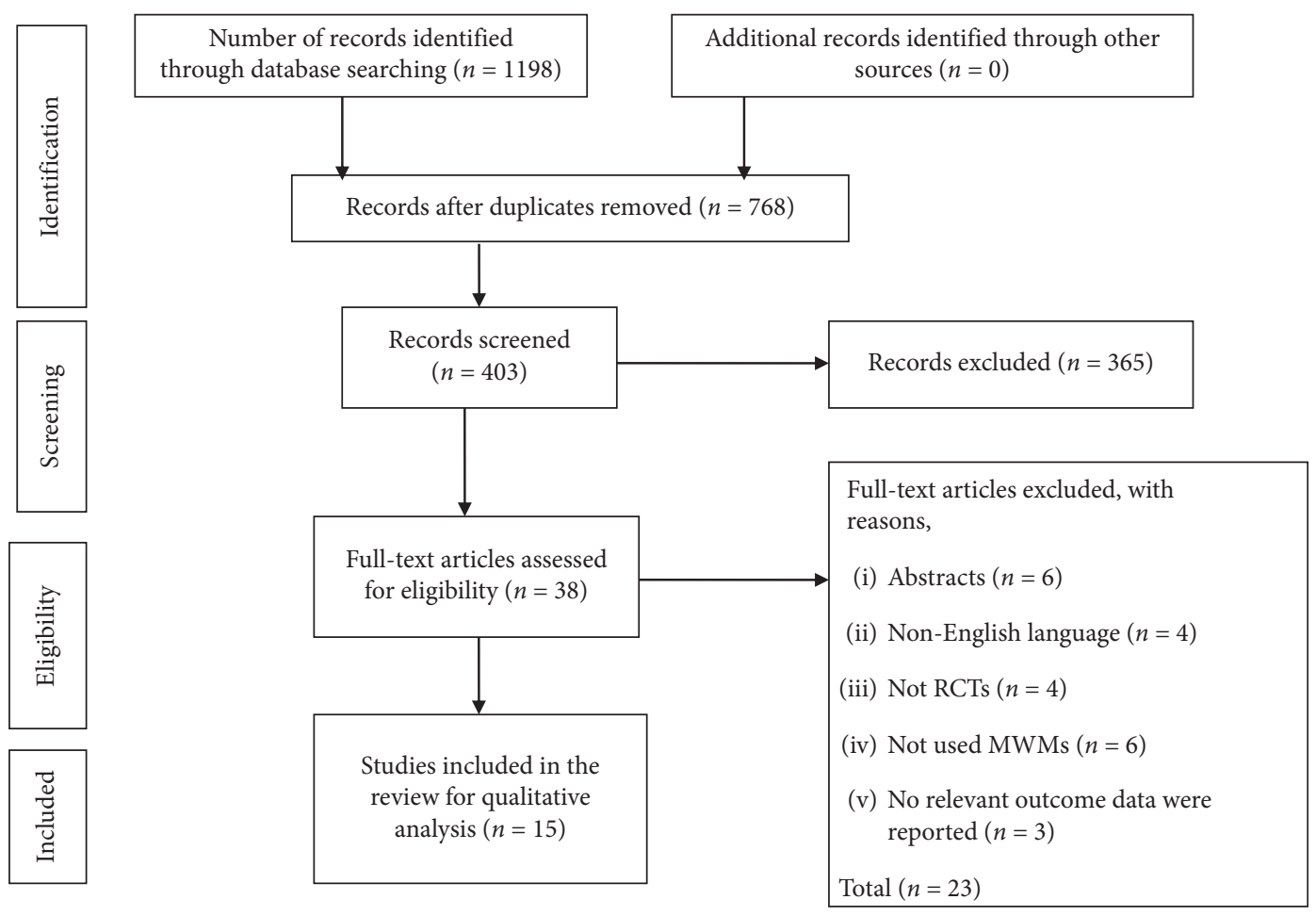

FIgURE 1: PRISMA flowchart of the study.

systematically evaluate the effectiveness of MWM among subjects with knee OA. In this review, 15 recent RCTs were included, which investigated the effectiveness of MWM in subjects with knee $\mathrm{OA}$ as compared with control interventions.

Most of the included studies published that MWMs is effective in improving pain, range of motion, and physical functioning in patients with knee OA. Most of the studies used the same outcome measure, particularly VAS, WOMAC, and knee ROM, for pain and functional impairment. Ten of the trials had assessed pain using a VAS $[5,31-34,36-38,40,44]$, three trials used the NPRS $[35,39,43]$, and the Knee injury and Osteoarthritis Outcome Scores (KOOS) pain subscale in one study [41] suggested that MWM had positive effects for subjects with knee OA on pain reduction. The results in this review are consistent with the previous systematic reviews on peripheral joints reporting positive clinical effects of MWM [23, 25, 28].

Shenouda [31] reported that MWM had positive effects for subjects with knee OA on pain reduction and functional disability. Besides, MWM has no statistically significant difference in the improvement of knee ROM in both the interventional and control groups. However, in within- and between-group analysis of pre- and posttreatment, there was statistical significance in all outcome measures. In contrast, a study conducted by Kandada andHeggannavar [32] showed that the intergroup analysis shows an insignificant difference in all the outcome measures. But, the intragroup comparison shows a significant difference in pain reduction, functional improvement, and knee ROM.

Another study investigated by Gupta et al. [33] showed that MWM had significant improvement in pain reduction, functional disability, and knee joint proprioception in OA knee participants. This could mean MWM may have had beneficial effects on joint nutrition because of the squeezing out of the fluid during each compression and imbibing of fluid when the compression is removed [45]. Normally, squeezing occurs when the mobilization technique is performed and imbibing of fluid occurs when the joint is relaxed. This could possibly be the reason for a reduction in pain and a subsequent improvement in ROM and function that was found at the end of the treatment session. Likewise, Lalnunpuii et al. [5] reported more significant relieving pain, increasing ROM, and functional capacity were found in the intervention group compared to the control group in females with knee OA. This could be beacuse MWM might provide a stretching effect on the joint capsules and muscles, thus restoring normal arthrokinematics or decreasing pain by stimulation of joint mechanoreceptors, which consequently inhibits nociceptive stimuli and improved motor control [46, 47]. Kulkarni and Kamat [34] showed that significant reductions in pain $(P<0.05)$ and improvement in 6-minute walk test distance covered during posttreatment sessions in both groups. However, posttreatment distance covered in the experimental group $($ mean $=37, \mathrm{SD}=16.882)$ was greater than that in the control group (mean $=35$, $\mathrm{SD}=23.146)$. Besides, Rao et al. [35] reported that both groups have shown a significant effect in reducing pain and improving functional mobility in subjects with knee OA immediately after treatment. Similarly, the study by Kaya Mutlu et al. [36] showed that MWM is superior in reducing pain, improving quadriceps muscle strength, knee range of motion, and functional level than the control group in knee OA participants. This could be due to the repeated motion of 
TABLE 2: Summary of included randomized control trials.

\begin{tabular}{|c|c|c|c|c|c|c|}
\hline Authors (year) & $\begin{array}{c}\text { Patient characteristics, } \\
\text { sample size, and mean } \\
\text { age }\end{array}$ & Intervention & $\begin{array}{l}\text { Frequency, } \\
\text { follow-up } \\
\text { time }\end{array}$ & $\begin{array}{l}\text { Outcome } \\
\text { measure }\end{array}$ & Results & Conclusion \\
\hline $\begin{array}{l}\text { Shenouda } \\
\text { (2013) [31] }\end{array}$ & $\begin{array}{l}\text { Source }: 45 \text { outpatients } \\
\begin{array}{c}(\mathrm{GA}=15, \mathrm{~GB}=15 \\
\mathrm{GC}=15) \text { and mean } \\
\text { age }(\mathrm{S} . \mathrm{D}): \\
\mathrm{GA}=51.93 \pm 6.51 \\
\mathrm{~GB}=52.2 \pm 5.44, \text { and } \\
\mathrm{GC}=50.07 \pm 5.73\end{array}\end{array}$ & $\begin{aligned} \mathrm{GA}= & \text { MWM plus } \\
& \text { exercise } \\
\mathrm{GB} & =\text { SWT plus } \\
& \text { exercise } \\
\mathrm{GC}= & \text { only exercise }\end{aligned}$ & $\begin{array}{l}\text { Thrice per } \\
\text { week for } 4 \\
\text { weeks }\end{array}$ & $\begin{array}{l}\text { VAS } \\
\text { WOMAC } \\
\text { ROM }\end{array}$ & $\begin{array}{c}\text { Significant } \\
\text { difference in pain } \\
\text { and functional } \\
\text { disability was } \\
\text { found in GA and } \\
\text { GC. But, no } \\
\text { significance } \\
\text { difference was } \\
\text { found between GA } \\
\text { and GC for ROM }\end{array}$ & $\begin{array}{c}\text { MWM was effective } \\
\text { in relieving knee } \\
\text { pain and functional } \\
\text { disability }\end{array}$ \\
\hline $\begin{array}{l}\text { Kandada and } \\
\text { Heggannavar } \\
(2015)[32]\end{array}$ & $\begin{array}{l}\text { Source }: 64 \text { outpatients } \\
\quad(\mathrm{GA}=32, \mathrm{~GB}=32) \\
\text { and mean age }(\mathrm{S} . \mathrm{D}): \\
\mathrm{GA}=50.13 \pm 6.94 \text { and } \\
\mathrm{GB}=54.72 \pm 6.25\end{array}$ & $\begin{aligned} \mathrm{GA}= & \text { MWM plus } \mathrm{CPT} \\
\mathrm{GB}= & \text { MIMG protocol } \\
& \text { plus } \mathrm{CPT}\end{aligned}$ & 2 weeks & $\begin{array}{c}\text { VAS } \\
\text { ROM } \\
\text { WOMAC }\end{array}$ & $\begin{array}{c}\text { Significant } \\
\text { intragroup } \\
(P<0.001) \\
\text { difference was } \\
\text { found. But, } \\
\text { intergroup } \\
\text { comparison is not } \\
\text { significant in all } \\
\text { variables }\end{array}$ & $\begin{array}{l}\text { Both MWM and } \\
\text { MIMG protocol are } \\
\text { effective in treating } \\
\text { OA knee }\end{array}$ \\
\hline $\begin{array}{l}\text { Gupta and } \\
\text { Heggannavar } \\
(2015)[33]\end{array}$ & $\begin{array}{l}\text { Source }: 60 \text { outpatients } \\
(\mathrm{GA}=20, \mathrm{~GB}=20, \\
\mathrm{GC}=20) \text { and mean } \\
\text { age }(\mathrm{S} . \mathrm{D}): \\
\mathrm{GA}=54.10 \pm 6.69 \\
\mathrm{~GB}=50.95 \pm 5.97, \text { and } \\
\mathrm{GC}=53.35 \pm 6.34\end{array}$ & $\begin{array}{c}\text { GA = MWM plus CPT } \\
\text { GB = proprioceptive } \\
\text { exercise plus CPT } \\
\text { GC = proprioceptive } \\
\text { exercise plus MWM } \\
\text { plus CPT }\end{array}$ & $\begin{array}{l}3 \text { sets of } 10 \\
\text { repetitions, } 1 \\
\text { session per } \\
\text { day for } 2 \\
\text { weeks }\end{array}$ & $\begin{array}{l}\text { VAS } \\
\text { WOMAC } \\
\text { ROM }\end{array}$ & $\begin{array}{l}\text { There were } \\
\text { statistically } \\
\text { significant changes } \\
\text { in all outcome } \\
\text { measures of GA } \\
\text { and GC }\end{array}$ & $\begin{array}{c}\text { Statistically } \\
\text { significant } \\
\text { improvement was } \\
\text { noted in knee joint } \\
\text { proprioception on } \\
\text { OA knee } \\
\text { participants with } \\
\text { Mulligan's MWM }\end{array}$ \\
\hline $\begin{array}{l}\text { Lalnunpuii } \\
\text { et al. (2017) [5] }\end{array}$ & $\begin{array}{l}\text { Source }: 45 \text { outpatients } \\
\begin{array}{c}(\mathrm{GA}=15, \mathrm{~GB}=15, \\
\mathrm{GC}=15) \text { and mean } \\
\text { age }(\mathrm{S} . \mathrm{D}): \\
\mathrm{GA}=49.46 \pm 5.48 \\
\mathrm{~GB}=48.46 \pm 6.86, \text { and } \\
\mathrm{GC}=47.93 \pm 5.61\end{array}\end{array}$ & $\begin{array}{c}\text { GA }=\text { MWM plus } \\
\text { exercise } \\
\text { GB }=\text { Maitland } \\
\text { mobilization plus } \\
\text { exercise } \\
\text { GC }=\text { exercise only }\end{array}$ & $\begin{array}{l}\text { Thrice per } \\
\text { week for } 4 \\
\text { weeks }\end{array}$ & $\begin{array}{c}\text { VAS } \\
\text { ROM } \\
\text { WOMAC }\end{array}$ & $\begin{array}{l}\text { All outcome } \\
\text { parameters } \\
(p<0.05) \text { are } \\
\text { statistically } \\
\text { improved in the } \\
\text { experimental } \\
\text { group compared } \\
\text { with the control } \\
\text { group }\end{array}$ & $\begin{array}{l}\text { MWM is more } \\
\text { effective than } \\
\text { Maitland } \\
\text { mobilization in } \\
\text { relieving pain and } \\
\text { increasing ROM and } \\
\text { functional capacity } \\
\text { in females with knee } \\
\text { OA }\end{array}$ \\
\hline $\begin{array}{l}\text { Kulkarni and } \\
\text { Kamat (2017) } \\
{[34]}\end{array}$ & $\begin{array}{l}\text { Source }: 30 \text { outpatients } \\
(\mathrm{GA}=15, \mathrm{~GB}=15) \\
\text { and mean age: not } \\
\text { stated }\end{array}$ & $\begin{array}{c}\mathrm{GA}=\mathrm{MWM} \text { plus } \mathrm{CPT} \\
\mathrm{GB}=\mathrm{CPT}\end{array}$ & $\begin{array}{l}\text { One session } \\
\text { per day for } 3 \\
\text { days }\end{array}$ & $\begin{array}{c}\text { VAS } \\
\text { 6-minute } \\
\text { walk test }\end{array}$ & $\begin{array}{l}\text { Statistically } \\
\text { significant } \\
(p<0.05) \\
\text { reduction in VAS } \\
\text { and marked } \\
\text { improvement in } \\
\text { the distance } \\
\text { covered in the } \\
\text { experimental } \\
\text { group }\end{array}$ & $\begin{array}{l}\text { MWM was effective } \\
\text { in reducing pain, } \\
\text { and showed marked } \\
\text { improvement in the } \\
6 \text {-minute walk test } \\
\text { in the experimental } \\
\text { group }\end{array}$ \\
\hline $\begin{array}{l}\text { Rao et al. } \\
(2018) \text { [35] }\end{array}$ & $\begin{array}{c}\text { Source }: 30 \text { outpatients } \\
(\mathrm{GA}=15, \mathrm{~GB}=15) \\
\text { and mean age } \\
51.2 \pm 9.2\end{array}$ & $\begin{array}{c}\text { GA = MWM followed } \\
\text { by Maitland } \\
\text { mobilization } \\
\text { GB = Maitland } \\
\text { mobilization followed } \\
\text { by MWM }\end{array}$ & $\begin{array}{l}1-3 \\
\text { oscillations } \\
\text { per second, } 3 \\
\text { repetitions, } \\
\text { for three days }\end{array}$ & $\begin{array}{c}\text { NPRS } \\
\text { TUG } \\
\text { Pain-free } \\
\text { squat angle }\end{array}$ & $\begin{array}{c}\text { Within } \\
\text { intervention, both } \\
\text { groups showed } \\
\text { significant changes } \\
(p<0.001) \text { in all } \\
\text { outcome measures }\end{array}$ & $\begin{array}{l}\text { Both are equally } \\
\text { effective in reducing } \\
\text { pain and improving } \\
\text { functional mobility } \\
\text { and pain-free squat } \\
\text { angle for knee OA }\end{array}$ \\
\hline
\end{tabular}


TABle 2: Continued.

\begin{tabular}{|c|c|c|c|c|c|c|}
\hline Authors (year) & $\begin{array}{c}\text { Patient characteristics, } \\
\text { sample size, and mean } \\
\text { age }\end{array}$ & Intervention & $\begin{array}{l}\text { Frequency, } \\
\text { follow-up } \\
\text { time }\end{array}$ & $\begin{array}{l}\text { Outcome } \\
\text { measure }\end{array}$ & Results & Conclusion \\
\hline $\begin{array}{l}\text { Kaya Mutlu } \\
\text { et al. (2018) } \\
{[36]}\end{array}$ & $\begin{array}{c}\text { Source }: 72 \text { outpatients } \\
(\mathrm{GA}=24, \mathrm{~GB}=24, \\
\begin{array}{c}\mathrm{G}=24) \text { and mean age } \\
(\mathrm{S} . \mathrm{D}): \\
\mathrm{GA}=54.19 \pm 7.34, \\
\mathrm{~GB}=56.29 \pm 6.64, \text { and } \\
\mathrm{GC}=57.77 \pm 6.24\end{array}\end{array}$ & $\begin{array}{c}\mathrm{GA}=\text { MWM plus } \\
\text { exercise } \\
\mathrm{GB}=\mathrm{PJM} \text { plus } \\
\text { exercise } \\
\text { GC= electrotherapy } \\
\text { plus exercise }\end{array}$ & $\begin{array}{l}\text { Thrice per } \\
\text { week at } 1- \\
\text { year follow- } \\
\text { up }\end{array}$ & $\begin{array}{l}\text { WOMAC } \\
\text { VAS } \\
\text { ROM } \\
\text { ALF }\end{array}$ & $\begin{array}{l}\text { WOMAC, VAS, } \\
\text { and knee ROM are } \\
\text { significantly } \\
\text { improved in the } \\
\text { experimental } \\
\text { group compared to } \\
\text { the control group }\end{array}$ & $\begin{array}{l}\text { MWM and PJM } \\
\text { were superior to the } \\
\text { control group in } \\
\text { pain, knee ROM, } \\
\text { quadriceps muscle } \\
\text { strength, and } \\
\text { functional level }\end{array}$ \\
\hline $\begin{array}{l}\text { Varma and } \\
\text { Purohit (2018) } \\
\text { [37] }\end{array}$ & $\begin{array}{l}\text { Source }: 36 \text { outpatients } \\
\qquad \begin{array}{c}(\mathrm{GA}=12, \mathrm{~GB}=12, \\
\mathrm{GC}=12) \text { and mean } \\
\text { age }(\mathrm{S} . \mathrm{D})= \\
\mathrm{GA}=50 \pm 6.33 \text {, } \\
\mathrm{GB}=58 \pm 5.68, \text { and } \\
\mathrm{GC}=55.75 \pm 4.88\end{array}\end{array}$ & $\begin{array}{c}\mathrm{GA}=\mathrm{MWM} \text { plus CPT } \\
\mathrm{GB}=\mathrm{KT} \text { plus } \mathrm{CPT} \\
\mathrm{GC}=\text { only } \mathrm{CPT}\end{array}$ & $\begin{array}{l}\text { Thrice per } \\
\text { week for } 2 \\
\text { weeks }\end{array}$ & $\begin{array}{c}\text { VAS } \\
\text { WOMAC }\end{array}$ & $\begin{array}{c}\text { There was a } \\
\text { statistically } \\
\text { significant } \\
\text { difference in each } \\
\text { group and between } \\
\text { groups } \\
\text { Significant } \\
\text { between-group } \\
\text { differences were } \\
\text { found }\end{array}$ & $\begin{array}{l}\text { Both MWM and KT } \\
\text { reduce pain and } \\
\text { improve function, } \\
\text { but there was a } \\
\text { better improvement } \\
\text { in group A }\end{array}$ \\
\hline $\begin{array}{l}\text { Kiran et al. } \\
(2018) \text { [38] }\end{array}$ & $\begin{array}{c}\text { Source }: 62 \text { outpatients } \\
\begin{array}{c}(\mathrm{GA}=31, \mathrm{~GB}=31) \text { and } \\
\text { mean age }(\mathrm{S} . \mathrm{D}): \\
47.47 \pm 0.61\end{array}\end{array}$ & $\begin{array}{c}\mathrm{GA}=\mathrm{MWM} \text { plus } \mathrm{CPT} \\
\mathrm{GB}=\text { Maitland } \\
\text { mobilization plus } \mathrm{CPT}\end{array}$ & $\begin{array}{l}3 \text { sessions per } \\
\text { week for } 2 \\
\text { weeks }\end{array}$ & $\begin{array}{c}\text { VAS } \\
\text { ROM } \\
\text { WOMAC }\end{array}$ & $\begin{array}{c}\text { The mean } \\
\text { differences of both } \\
\text { treatment } \\
\text { interventions were } \\
\text { significant }\end{array}$ & $\begin{array}{l}\text { Patients in both } \\
\text { groups showed } \\
\text { improvement in } \\
\text { pain, ROM, and } \\
\text { functions }\end{array}$ \\
\hline $\begin{array}{l}\text { Bhagat et al. } \\
(2020) \text { [39] }\end{array}$ & $\begin{array}{l}\text { Source }: 30 \text { outpatients } \\
\quad(\mathrm{GA}=15, \mathrm{~GB}=15) \\
\text { and mean age }(\mathrm{S} . \mathrm{D}): \\
\mathrm{GA}=53.73 \pm 7.06 \text {, and } \\
\mathrm{GB}=56.87 \pm 9.35\end{array}$ & $\begin{array}{c}\mathrm{GA}=\mathrm{MWM} \\
\mathrm{GB}=\text { Sham }\end{array}$ & $\begin{array}{l}3 \text { sets with } 10 \\
\text { repetitions, } \\
\text { duration of } \\
\text { follow-up not } \\
\text { stated }\end{array}$ & $\begin{array}{l}\text { NPRS } \\
\text { TUG }\end{array}$ & $\begin{array}{l}\text { NPRS and TUG } \\
\text { are significantly } \\
\text { improved in GA } \\
\text { compared to GB } \\
\text { after intervention }\end{array}$ & $\begin{array}{l}\text { MWM was effective } \\
\text { in improving pain } \\
\text { and functional } \\
\text { mobility in } \\
\text { individuals with } \\
\text { knee OA }\end{array}$ \\
\hline $\begin{array}{l}\text { Alkhawajah } \\
\text { and Alshami } \\
(2019)[40]\end{array}$ & $\begin{array}{l}\text { Source }: 40 \text { outpatients } \\
\qquad \begin{array}{l}\mathrm{GA}=20, \mathrm{~GB}=20) \\
\text { and mean age }(\mathrm{S} . \mathrm{D}): \\
\mathrm{GA}=56.5 \pm 7.6 \text { and } \\
\mathrm{GB}=56.6 \pm 8.5\end{array}\end{array}$ & $\begin{array}{c}\mathrm{GA}=\mathrm{MWM} \\
\mathrm{GB}=\text { sham }\end{array}$ & $\begin{array}{l}3 \text { sets with } 10 \\
\text { repetitions } \\
\text { for } 2 \text { days }\end{array}$ & $\begin{array}{c}\text { VAS } \\
\text { ROM } \\
\text { WOMAC } \\
\text { TUG }\end{array}$ & $\begin{array}{c}\text { GA showed } \\
\text { significant } \\
\text { improvement in } \\
\text { pain, TUG, and } \\
\text { knee flexion ROM } \\
(p \leq 0.026) \\
\text { But, WOMAC and } \\
\text { knee extension } \\
\text { ROM }(p=0.067) \\
\text { were not } \\
\text { significant }\end{array}$ & $\begin{array}{l}\text { MWM was superior } \\
\text { than sham in pain, } \\
\text { physical function } \\
\text { (walking), knee } \\
\text { flexion and } \\
\text { extension muscle } \\
\text { strength, and knee } \\
\text { flexion ROM for at } \\
\text { least } 2 \text { days in } \\
\text { patients with knee } \\
\text { OA }\end{array}$ \\
\hline $\begin{array}{l}\text { Saddam } \\
\text { Hussain Shaik } \\
\text { et al. (2019) } \\
\text { [41] }\end{array}$ & $\begin{array}{c}\text { Source }: 40 \text { outpatients } \\
(\mathrm{GA}=20, \mathrm{~GB}=20), \\
\text { mean age not } \\
\text { mentioned }\end{array}$ & $\begin{array}{c}\mathrm{GA}=\mathrm{MWM} \text { plus } \mathrm{CPT} \\
\mathrm{GB}=\text { Maitland } \\
\text { mobilization plus } \mathrm{CPT}\end{array}$ & $\begin{array}{c}\text { Three } \\
\text { sessions per } \\
\text { week for } 6 \\
\text { weeks }\end{array}$ & $\begin{array}{c}\text { KOOS } \\
\text { Quadriceps } \\
\text { peak torque }\end{array}$ & $\begin{array}{c}\text { GA showed more } \\
\text { statistical } \\
\text { significance in } \\
\text { improving pain } \\
\text { and quadriceps } \\
\text { peak torque than } \\
\text { GB }\end{array}$ & $\begin{array}{l}\text { MWM was more } \\
\text { effective than } \\
\text { Maitland } \\
\text { mobilization }\end{array}$ \\
\hline $\begin{array}{l}\text { Pawar et al. } \\
(2019) \text { [42] }\end{array}$ & $\begin{array}{l}\text { Source }: 20 \text { outpatients } \\
(\mathrm{GA}=10, \mathrm{~GB}=10) \\
\text { mean age not stated }\end{array}$ & $\begin{array}{c}\mathrm{GA}=\mathrm{MWM} \\
\mathrm{GB}=\mathrm{McC} \text { Connell } \\
\text { patella taping }\end{array}$ & $\begin{array}{l}\text { Each session } \\
15-20 \\
\text { minutes, four } \\
\text { days a week }\end{array}$ & VAS & $\begin{array}{c}\text { VAS is } \\
\text { significantly } \\
\text { improved in the } \\
\text { experimental } \\
\text { group }(P<0.0001) \\
\text { compared to the } \\
\text { control group } \\
(P=0.0558)\end{array}$ & $\begin{array}{l}\text { MWM is } \\
\text { comparatively more } \\
\text { beneficial in } \\
\text { reducing pain than } \\
\text { taping in OA knee } \\
\text { patients }\end{array}$ \\
\hline
\end{tabular}


TABLE 2: Continued.

\begin{tabular}{|c|c|c|c|c|c|c|}
\hline Authors (year) & $\begin{array}{c}\text { Patient characteristics, } \\
\text { sample size, and mean } \\
\text { age }\end{array}$ & Intervention & $\begin{array}{l}\text { Frequency, } \\
\text { follow-up } \\
\text { time }\end{array}$ & $\begin{array}{l}\text { Outcome } \\
\text { measure }\end{array}$ & Results & Conclusion \\
\hline $\begin{array}{l}\text { Mahmooda } \\
\text { et al. }(2020) \\
{[43]}\end{array}$ & $\begin{array}{l}\text { Source }: 30 \text { outpatients } \\
(\mathrm{GA}=15, \mathrm{~GB}=15) \\
\text { and mean age }(\mathrm{S} . \mathrm{D})= \\
52.80 \pm 6.32\end{array}$ & $\begin{array}{c}\text { GA = MWM plus } \\
\text { usual care } \\
\text { GB = Myofacial } \\
\text { release plus usual care }\end{array}$ & $\begin{array}{l}\text { Once a day, } 5 \\
\text { days per week } \\
\text { for two weeks }\end{array}$ & $\begin{array}{c}\text { NPRS } \\
\text { ROM } \\
\text { WOMAC }\end{array}$ & $\begin{array}{l}\text { Pain and ROM } \\
\text { were improved in } \\
\text { GA }(p<0.05) \text {. But, } \\
\text { reduction of } \\
\text { stiffness and } \\
\text { improvement of } \\
\text { physical function } \\
\text { were seen in group } \\
\text { B }(p<0.05)\end{array}$ & $\begin{array}{c}\text { MWM and } \\
\text { myofacial release } \\
\text { were effective for } \\
\text { knee OA in pain, } \\
\text { ROM, and } \\
\text { functional abilities. } \\
\text { However, MWM } \\
\text { produced more } \\
\text { quick outcomes } \\
\text { than myofacial }\end{array}$ \\
\hline $\begin{array}{l}\text { Nigam et al. } \\
(2020)[44]\end{array}$ & $\begin{array}{l}\text { Soure }: 40 \text { outpatients } \\
(\mathrm{GA}=20, \mathrm{~GB}=20) \\
\text { and mean age }(\mathrm{S} . \mathrm{D}): \\
\mathrm{GA}=58.5(4.36) \text { and } \\
\mathrm{GB}=59.4(6.57)\end{array}$ & $\begin{array}{c}\mathrm{GA}=\text { MWM plus } \\
\text { usual care } \\
\mathrm{GB}=\text { usual care }\end{array}$ & $\begin{array}{l}\text { Three sets of } \\
6-10 \\
\text { repetitions } \\
\text { over two } \\
\text { weeks at } 6 \\
\text { months }\end{array}$ & $\begin{array}{l}\text { WOMAC } \\
\text { VAS } \\
\text { ROM } \\
\text { TUG }\end{array}$ & $\begin{array}{l}\text { Significant effect of } \\
\text { MWM in favor of } \\
\text { GA for WOMAC } \\
\text { and VAS was } \\
\text { found. But, no } \\
\text { significant } \\
\text { difference between } \\
\text { GA and GB was } \\
\text { found for knee } \\
\text { ROM and TUG }\end{array}$ & $\begin{array}{l}\text { MWM provided } \\
\text { clinically significant } \\
\text { improvements in } \\
\text { disability, pain, and } \\
\text { functional activities } \\
\text { six months later }\end{array}$ \\
\hline
\end{tabular}

Abbreviations: OA, osteoarthritis; MWM, Mulligan's movement with mobilization; MIMG, Macquarie injury management group; SWT, shock wave therapy; KT, Kinesio Taping; GA, group A (experimental group), GB; group B, GC; group C, CPT; conventional physical therapy, PJM; passive joint mobilization, VAS; Visual Analog Scale; WOMAC; Western Ontario and McMaster Universities Osteoarthritis Index, ROM; range of motion, NPRS; Numeric Pain Rating Scale, TUG; Time Up and Go, ALF; Aggregated Locomotor Function, KOOS; Knee injury and Osteoarthritis Outcome Scale.

MWM, which might alter the concentrations of anti-inflammatory mediators in the joint, which might consequently inhibit nociceptors [48]. Another possible reason could be due to psychological effects such as a reduction in fear avoidance associated with movement [49].

Varma and Purohit [37] found that MWM combined with conventional exercise groups showed better significant improvement in reducing pain, improving function than the conventional exercise group after 2 weeks of intervention. In the intervention group, the improvements could be because of biomechanical and neurophysiological mechanisms of MWM that may produce pain at the spinal level (pain gate mechanisms) [50]. Besides, a study by Kiran et al. [38] found that both groups showed a significant effect on the improvement of pain, knee range of motion, and functional ability after two weeks of intervention in patients with knee OA.

Bhagat et al. [39] investigated that MWM produced direct effects in reducing knee pain and improving functional mobility in knee OA as compared with the placebo group. This could be because of the biomechanical mechanisms in Mulligan's MWM concept [51, 52]. The correction of positional faults by the treatment glides used in the intervention group could have quickly repaired the normal kinematics of the osteoarthritic knee producing instant pain relief. Furthermore, a study conducted by Alkhawajah and Alshami [40] suggested that MWM had a superior effect in reducing pain, improving physical function (TUG), and knee flexion than the sham group. However, WOMAC $(P=0.067)$ has no significant effect on patients with knee $\mathrm{OA}$. This could be because the grade of OA was relatively low, which may denote a nonmajor limitation of functional activity and the duration of the follow-up was short (2 days) which might not be sufficient for a perceived improvement in daily activities.

Another study conducted by Saddam Hussain Shaik et al. [41] reported that MWM had a significant improvement in pain reduction and quadriceps peak torque compared to the control group. In the intervention group for pain, the reduction may be because of the inspiration that MWM sedates an agitated, expedited system, significantly the dorsal horn, by offending it with painless normality it is been freckled to receive. Another attainable reason may be central mechanisms area unit concerned as there is activation of the nonopioid mediate drizzling pain restrictive system $[25,53]$. In addition, the mechanism responsible for the improvement of quadriceps peak torque is believed to be the arthrokinetic reflex, defined as the influence of joint mechanoreceptor afferents on muscles around the joint [54]. Pawar et al. studied the effect of MWM in subjects with knee OA. A randomized control trial shows that the MWM group showed greater improvement when compared with the control group on pain [42].

Shamim et al. [43] investigated that reduction of pain and ROM showed a significant effect in the MWM group compared to the control group. In the study conducted by Nigam et al. [44] MWM combined with usual care suggested that there is a significant effect of MWM in favor of the intervention group for WOMAC and VAS compared to the control group. The superior pain reduction in the experimental group could be because MWM may decrease nociceptive inputs while increasing nonnociceptive inputs via 
TABLE 3: Risk-of-bias analysis.

Random sequence

Selection bias
Kandada and Heggannavar [32]

Lalnunpuii et al. [5] Rao et al. [35]

Kaya Mutlu et al. [36]

Varma and Purohit [37] Bhagat et al. [39] Alkhawajah and Alshami [40]

Mahmooda et al. [43] Nigam et al. [44]

Lalnunpuii et al. [5] Rao et al. [35]

Kaya Mutlu et al. [36] Bhagat et al. [39]

Alkhawajah and Alshami [40] Nigam et al. [44]

Lalnunpuii et al. [5] Rao et al. [35]

Performance bias Blinding of participants and treating therapist

Kaya Mutlu et al. [36] Bhagat et al. [39]

Alkhawajah and Alshami [40] Nigam et al. [44]

Lalnunpuii et al. [5] Rao et al. [35]

Detection bias $\quad$ Blinding of assessor

Bhat et a. [39] Bhagat et al. [39]

Alkhawajah and Alshami [40] Nigam et al. [44] Shenouda [31]

Kandada and Heggannavar [32]

Gupta and Heggannavar [33]

Lalnunpuii et al. [5]

Kulkarni and Kamat [34] Rao et al. [35]

Kaya Mutlu et al. [36]

Varma and Purohit [37] Kiran et al. [38] Bhagat et al. [39] Alkhawajah and Alshami [40] Saddam Hussain Shaik et al. [41] Pawar et al [42]

Mahmooda et al. [43] Nigam et al. [44]

activation of peripheral mechanoreceptors [53]. However, there were no significant differences between groups for functional mobility as measured with the TUG immediately after the intervention. The improvement seen in both groups could be due to the positive effects of exercise. Exercise reduces pain, increases muscle strength, and improves control around the affected joint [55].

4.1. Limitations. This systematic review has some limitations. The first limitation of this review is that a language bias is possible as only those studies that were available as full text in English were included. The second limitation of this review is that the outcome measures were not similar across the RCTs included in this review. A meta-analysis was not conducted because of the heterogeneous nature of the studies, and this could have been valuable for the effect of mobilization with movement. Third, studies with short follow-up duration were included because a longer treatment duration could likely result in a significant intergroup difference. Lastly, only one of the available studies scrutinized the long-term effects of the MWMs on knee OA [44]. Based on the systematic appraisal of the current literature, any future research studies should consider the limitations of the previous studies in order to improve the quality of evidence in this field.

4.2. Clinical Implication. This review suggests that MWM appears to reduce pain, improves knee range of motion, and improve physical functioning in subjects with knee osteoarthritis. 


\section{Conclusions}

The findings of this systematic review suggest that Mulligan's MWM could be a treatment option among subjects with knee osteoarthritis. This review supports the evidence that Mulligan's MWM reduces pain, improves knee range of motion, and physical functioning of subjects with knee osteoarthritis.

\section{Ethical Approval}

It does not require ethical approval since the present study was a review of previously published literature.

\section{Conflicts of Interest}

The authors report no potential conflicts of interest in this work with respect to the research, authorship, and/or publication of this article.

\section{Authors' Contributions}

All authors have contributed to the work reported, the conception, study design, execution, acquisition of data, analysis, and interpretation, and writing or critically reviewing the article, agreed on the journal to which the article was submitted, and reviewed and agreed on all versions of the article before submission. Finally, the authors agree to take responsibility and be accountable for the contents of this article.

\section{References}

[1] D. Ofluoglu and O. Ofluoglu, "Assessment of disease activity and progression of osteoarthritis with using molecular markers of cartilage and synovium turnover," Current Rheumatology Reviews, vol. 1, no. 1, pp. 29-32, 2005.

[2] L. Busija, L. Bridgett, S. R. M. Williams et al., "Osteoarthritis," Best Practice \& Research Clinical Rheumatology, vol. 24, no. 6, pp. 757-768, 2010.

[3] D. T. Felson, Y. Zhang, M. T. Hannan et al., "The incidence and natural history of knee osteoarthritis in the elderly, the framingham osteoarthritis study," Arthritis \& Rheumatism, vol. 38, no. 10, pp. 1500-1505, 1995.

[4] D. Solanki and V. Kage, "Effectiveness of medial mulligan glide versus internal rotation mulligan glide in knee osteoarthritis-a randomized clinical trial," Romanian Journal of Physical Therapy/Revista Romana de Kinetoterapie.vol. 21, no. 35, 2015.

[5] A. Lalnunpuii, B. Sarkar, S. Alam, D. Equebal, and D. Biswas, "Efficacy of mulligan mobilisation as compared to maitland mobilisation in females with knee osteoarthritis:a double blind randomized controlled trial," International Journal of Therapies and Rehabilitation Research, vol. 6, no. 2, p. 37, 2017.

[6] E. Ciplak, S. Akturk, R. Buyukavci, and Y. Ersoy, "Efficiency of high intensity laser therapy in patients with knee osteoarthritis," Medicine Science| International Medical Journal, vol. 7, pp. 724-727, 2018.

[7] A. D. Woolf and B. Pfleger, "Burden of major musculoskeletal conditions," Bulletin of the World Health Organization, vol. 81, pp. 646-656, 2003.
[8] E. M. Ilieva, A. Oral, A. A. Küçükdeveci et al., "Osteoarthritis. The role of physical and rehabilitation medicine physicians. The European perspective based on the best evidence. A paper by the UEMS-PRM Section Professional Practice Committee," European Journal of Physical and Rehabilitation Medicine, vol. 49, no. 4, pp. 579-593, 2013.

[9] D. Hunter, "The epidemiology of osteoarthritis," Best Practice \& Research Clinical Rheumatology, vol. 28, pp. 5-15, 2014.

[10] G. Sakalauskienè and D. Jauniškienè, "Osteoarthritis: etiology, epidemiology, impact on the individual and society and the main principles of management," Medicina (Kaunas, Lithuania), vol. 46, no. 11, pp. 790-797, 2010.

[11] A. S. Anderson and R. F. Loeser, "Why is osteoarthritis an agerelated disease?" Best Practice \& Research Clinical Rheumatology, vol. 24, no. 1, pp. 15-26, 2010.

[12] B. R. Da Costa, S. Reichenbach, N. Keller et al., "Effectiveness of non-steroidal anti-inflammatory drugs for the treatment of pain in knee and hip osteoarthritis: a network meta-analysis," The Lancet, vol. 390, no. 10090, pp. e21-e33, 2017.

[13] M. S. M. Persson, J. Stocks, G. Varadi et al., "Predicting response to topical non-steroidal anti-inflammatory drugs in osteoarthritis: an individual patient data meta-analysis of randomized controlled trials," Rheumatology, vol. 59, no. 9, pp. 2207-2216, 2020.

[14] W. Zhang, G. Nuki, R. W. Moskowitz et al., "OARSI recommendations for the management of hip and knee osteoarthritis," Osteoarthritis and Cartilage, vol. 18, no. 4, pp. 476-499, 2010.

[15] O. S. Atik, "Can we treat knee osteoarthritis with photomedicine?" Photomedicine and Laser Surgery, vol. 33, no. 3, pp. 121-122, 2015.

[16] C. J. Page, R. S. Hinman, and K. L. Bennell, "Physiotherapy management of knee osteoarthritis," International Journal of Rheumatic Diseases, vol. 14, no. 2, pp. 145-151, 2011.

[17] H. Melese, A. Alamer, M. Hailu Temesgen, and F. Nigussie, "Effectiveness of kinesio taping on the management of knee osteoarthritis: a systematic review of randomized controlled trials," Journal of Pain Research, vol. 13, pp. 1267-1276, 2020.

[18] Y. Zheng, X. Duan, S. Qi et al., "Acupuncture therapy plus hyaluronic acid injection for knee osteoarthritis: a metaanalysis of randomized controlled trials," Evidence-Based Complementary and Alternative Medicine, vol. 2020, Article ID 4034105, 10 pages, 2020.

[19] A. Askari, S. A. Ravansalar, M. M. Naghizadeh et al., "The efficacy of topical sesame oil in patients with knee osteoarthritis: a randomized double-blinded active-controlled noninferiority clinical trial," Complementary Therapies in Medicine, vol. 47, Article ID 102183, 2019.

[20] N. Koonrungsesomboon, S. Teekachunhatean, S. Chansakaow, and N. Hanprasertpong, "Clinical efficacy and safety of yellow oil formulations 3 and 4 versus indomethacin solution in patients with symptomatic osteoarthritis of the knee: a randomized controlled trial," Evidence-Based Complementary and Alternative Medicine, vol. 2020, Article ID 5782178, 10 pages, 2020.

[21] Z.-P. Zeng, Y.-B. Liu, J. Fang, Y. Liu, J. Luo, and M. Yang, "Effects of Baduanjin exercise for knee osteoarthritis: a systematic review and meta-analysis," Complementary Therapies in Medicine, vol. 48, Article ID 102279, 2020.

[22] L. Voogt, J. De Vries, M. Meeus, F. Struyf, D. Meuffels, and J. Nijs, "Analgesic effects of manual therapy in patients with musculoskeletal pain: a systematic review," Manual Therapy, vol. 20, no. 2, pp. 250-256, 2015. 
[23] W. Hing, R. Bigelow, and T. Bremner, "Mulligan's mobilization with movement: a systematic review," Journal of Manual \& Manipulative Therapy, vol. 17, no. 2, pp. 39E-66E, 2009.

[24] B. R. Mulligan, Manual therapy: "Nags", "Snags", "Mwms" Etc, Plane View Services Ltd, Medina, USA, 2004.

[25] B. Vicenzino, W. Hing, T. Hall, and D. Rivett, Mobilisation with Movement: The Art and the Science, Elsevier, Amsterdam, Netherlands, 2011.

[26] B. Vicenzino, M. Branjerdporn, P. Teys, and K. Jordan, "Initial changes in posterior talar glide and dorsiflexion of the ankle after mobilization with movement in individuals with recurrent ankle sprain," Journal of Orthopaedic \& Sports Physical Therapy, vol. 36, no. 7, pp. 464-471, 2006.

[27] B. R. Mulligan, Manual therapy: "Nags", "Snags", "Mwms" Etc, Plane View Services Ltd, Wellington, Newzealand, 2004.

[28] K. Westad, F. Tjoestolvsen, and C. Hebron, "The effectiveness of Mulligan's mobilisation with movement (MWM) on peripheral joints in musculoskeletal (MSK) conditions: a systematic review," Musculoskeletal Science and Practice, vol. 39, pp. 157-163, 2019.

[29] D. Moher, "Preferred reporting items for systematic review and meta-analysis protocols (PRISMA-P) 2015 statement," Systematic Reviews, vol. 4, no. 1, 2015.

[30] N. A. De Morton, "The PEDro scale is a valid measure of the methodological quality of clinical trials: a demographic study," Australian Journal of Physiotherapy, vol. 55, no. 2, pp. 129-133, 2009.

[31] M. M. S. Shenouda, "Efficacy of extracorporeal Shock wave therapy versus mobilization with movement on pain, disability and range of motion in patients with knee osteoarthritis," Bulletin of Faculty of Physical Therapy, vol. 18, no. 1, 2013.

[32] S. Kandada and A. Heggannavar, "Effect of mulligans mwm versus Macquarie injury management group (mimg) protocol on pain and function in osteoarthritis of knee: a randomized clinical trial," International Journal of Therapies and Rehabilitation Research, vol. 4, no. 4, pp. 125-131, 2015.

[33] R. Gupta and A. Heggannavar, "Quantitative effects of proprioceptive exercises and mulligan's mwm in subjects with osteoarthritis knee-a randomized controlled trial," International Journal of Therapies and Rehabilitation Research, vol. 4, no. 4, p. 191, 2015.

[34] A. V. Kulkarni and M. M. Kamat, "A study to determine the effectiveness of mobilization with movement techniques in knee osteoarthritis pain," International Journal of Health Sciences and Research, vol. 7, no. 4, 2017.

[35] R. V. Rao, G. Balthillaya, A. Prabhu, and A. Kamath, "Immediate effects of maitland mobilization versus mulligan mobilization with movement in osteoarthritis knee-a randomized crossover trial," Journal of Bodywork and Movement Therapies, vol. 22, no. 3, pp. 572-579, 2018.

[36] E. Kaya Mutlu, E. Ercin, A. Razak Ozdıncler, and N. Ones, “A comparison of two manual physical therapy approaches and electrotherapy modalities for patients with knee osteoarthritis: a randomized three arm clinical trial," Physiotherapy Theory and Practice, vol. 34, no. 8, pp. 600-612, 2018.

[37] S. V. Varma and A. Purohit, "Effect of kinesio taping versus mulligan" s mobilization with movement on pain and function in subjects with osteoarthritis of knee: a comparative study," 2020.

[38] A. Kiran, M. J. Ijaz, M. M. Qamar, A. Basharat, A. Rasul, and W. Ahmed, "Comparison of efficacy of mulligan's mobilization with movement with maitland mobilization along with conventional therapy in the patients with knee osteoarthritis: a randomized clinical trial," Libyan International Medical University Journal, vol. 3, no. 1, p. 26, 2018.

[39] M. Bhagat, Y. R. Neelapala, and R. Gangavelli, "Immediate effects of Mulligan's techniques on pain and functional mobility in individuals with knee osteoarthritis: a randomized control trial," Physiotherapy Research International, vol. 25, no. 1, Article ID e1812, 2020.

[40] H. A. Alkhawajah and A. M. Alshami, "The effect of mobilization with movement on pain and function in patients with knee osteoarthritis: a randomized double-blind controlled trial," BMC Musculoskeletal Disorders, vol. 20, no. 1, p. 452, 2019.

[41] C. S. Saddam Hussain Shaik, K. Senthil Kumar, and K. Madhavi, "Compare the effectiveness of maitland mobilization and mulligan mobilization with movement on functional index in females with knee osteoarthritis," International Educational Scientific Research Journal, vol. 5, no. 3, 2019.

[42] B. R. Pawar, A. Jeganathan, and R. Monisha, "A comparative study to determine the effectiveness of the taping and Mulligan's mobilization with movement techniques on pain in knee osteoarthritis," Indian Journal of Public Health Research and Development, vol. 10, no. 7, p. 80, 2019.

[43] S. Mahmooda, I. Ishaq, M. Safdar, M. Sabir, A. Tahir, and S. Irshad, "Effects of Mulligan's mobilization with movements versus myofascial release in addition to usual care on pain and range in knee osteoarthritis," Rawal Medical Journal, vol. 45, no. 2, pp. 353-357, 2020.

[44] A. Nigam, K. H. Satpute, and T. M. Hall, "Long term efficacy of mobilisation with movement on pain and functional status in patients with knee osteoarthritis: a randomised clinical trial," Clinical Rehabilitation, vol. 35, no. 1, pp. 80-89, 2020.

[45] P. K. Levangie and C. C. Norkin, Joint Structure and Function: A Comprehensive Analysis, FA Davis Company, Philadelphia, PA, USA, 3rd. edition, 2000.

[46] M. Sterling and B. Vicenzino, "Pain and sensory system impairments that may be amenable to mobilisation with movement," Mobilisation with Movement: The Art and the Science Chatswood, pp. 86-92, Elsevier, Amsterdam, Netherlands, 2011.

[47] W. Hing, T. Hall, D. A. Rivett, B. Vicenzino, and B. Mulligan, The Mulligan Concept of Manual Therapy-eBook: Textbook of Techniques, Elsevier Health Sciences, Amsterdam, Netherlands, 2015.

[48] V. V. Sambajon, J. E. Cillo Jr, R. J. Gassner, and M. J. Buckley, "The effects of mechanical strain on synovial fibroblasts," Journal of Oral and Maxillofacial Surgery, vol. 61, no. 6, pp. 707-712, 2003.

[49] B. Vicenzino, T. Hall, W. Hing, and D. Rivett, "A new proposed model of the mechanisms of action of mobilisation with movement," Mobilisation with Movement: The Art and the Science, pp. 75-85, Elsevier, Amsterdam, Netherlands, 2011.

[50] Y. V. R. Neelapala, Y. R. S. Reddy, and R. Danait, "Effect of mulligan's posterolateral glide on shoulder rotator strength, scapular upward rotation in shoulder pain subjects-a randomized controlled trial," Journal of Musculoskeletal Research, vol. 19, no. 3, p. 1650014, 2016.

[51] J. E. Bialosky, M. D. Bishop, D. D. Price, M. E. Robinson, and S. Z. George, "The mechanisms of manual therapy in the treatment of musculoskeletal pain: a comprehensive model," Manual Therapy, vol. 14, no. 5, pp. 531-538, 2009. 
[52] M. D. Bishop, R. Torres-Cueco, C. W. Gay, E. Lluch-Girbés, J. M. Beneciuk, and J. E. Bialosky, "What effect can manual therapy have on a patient's pain experience?" Pain Management, vol. 5, no. 6, pp. 455-464, 2015.

[53] J. E. Bialosky, J. M. Beneciuk, M. D. Bishop et al., "Unraveling the mechanisms of manual therapy: modeling an approach," Journal of Orthopaedic \& Sports Physical Therapy, vol. 48, no. 1, pp. 8-18, 2018.

[54] H. Makofsky, S. Panicker, J. Abbruzzese et al., "Immediate effect of grade IV inferior hip joint mobilization on hip abductor torque: a pilot study," Journal of Manual \& Manipulative Therapy, vol. 15, no. 2, pp. 103-110, 2007.

[55] D. J. Leong and H. B. Sun, "Osteoarthritis-why exercise?" Journal of Exercise, Sports \& Orthopedics, vol. 1, no. 1, 2014. 